The Brock Review Volume 12 No. 1 (2011)

(C) Brock University

\title{
Siamese Cat
}

\section{Andrea Nicki}

I have been trying to show my cat

the same amount of high respect

as was shown to her ancestors of Siam

restricted to royal families and served on gold plates

Having comparatively meagre means I do my best

buying her lots of toys: soft crinkly balls, catnip pillows

sticks with hanging feathers

She likes to go out but we live near busy traffic

so I take her out on a long leash

Her favourite bird to hunt is the crow

perhaps tapping into genetic memories of more formidable distant ancestors

who would have had a much better chance at catching one

than my cat with her dainty, tentative paws

Her favourite toy is a stick with pink feathers

which I wave while she jumps and swats at it

She likes to hide under the dresser

and watch the feathers as they move across the floor

She understands that "zig-zag bird"

is just a game, that I am the one making the feathers

fly, soar, drop in altitude, circle, land

disappear behind a hedge of blanket

a tree-door

and that the feathers in her mouth are not a dead crow

She often plays with this feather-toy by herself

making it rise and fall

Amazed and admiring that she can derive so much enjoyment

from this poor facsimile of the natural world

I try to copy her, imagine that I too am in a world

that does not fall short of a rich ideal

where limitations can be magically transformed

consolations affording great delight

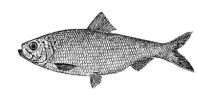

